illness and healthcare provision. The positive examples of individual leaders who had observed shortfalls and designed solutions to respond to the health needs of their local population inspired us to adopt similarly proactive approaches in our own clinical practice. Living and working in Sierra Leone developed our personal resilience and was emotionally impactful. Overall, a short-term program like GH-QEP not only benefits trainees personally and professionally, it might help increase specialty trainee application and retention. Furthermore, it could be expanded to incorporate a binational exchange program.

\section{G451(P) BLOOD TRANSFUSION SAFETY; KNOWLEDGE OF AMONG MEDICAL STAFFS PRE AND POST EDUCATIONAL INTERVENTION}

S Sahmoud, M El-Kalioby, E Ashry. Paediatrics, Suez Canal University, Ismailia, Egypt

10.1136/archdischild-2020-rcpch.389

The serious hazards of blood transfusion report showed that most of the errors reported in 2015 resulted from human factors and only $10 \%$ of them were not preventable, thus staff training on safe blood transfusion was strongly recommended. Aim To assess blood transfusion safety knowledge among medical staffs and how much it improves after intervention.

Methods A quasi-experimental study was conducted on 190 participants most of them were working on a tertiary nonteaching hospital for more than 8 years. A questionnaire was designed and validated through a pilot study after which all participants were invited to fill it pre and post educational intervention. The educational material has been prepared based on the WHO blood transfusion safety guidelines (WHO/EHT/10.05) in the form of leaflets and short power point presentations prepared by the researcher and reviewed by external experts in the field.

Results Near miss was identified by only half of the participants and around $78.3 \%, 63.2 \%$, and $60 \%$ of them correctly identified the indication of red blood cells, fresh frozen plasma, and platelet transfusion. These percentages were significantly improved post education. Only 50\% knew that it's not allowed to co-administrate drugs or IV fluids with the transfused blood and that rose to almost $80 \%$ after intervention. Consent information and correct patient identification were well known among most of the staff. Only $18.4 \%$ knew the pre transfusion screening protocol, which was increased to $85.8 \%$ post education. Almost $65.3 \%$ correctly responded to the transfusion reaction quiz with no marked change after intervention. Age and work experience were significant independent risk factors for poor knowledge of safety transfusion. Conclusion Transfusion safety knowledge needs further enhancement with more tailored training programs focusing on the topics that didn't show a significant change after our educational training such as the various transfusion reactions.

\section{G452(P) 'COUNTING THE UNCOUNTED': A DESCRIPTIVE STUDY OF THE DIAGNOSES PRESENTING TO A COMMUNITY PAEDIATRIC CLINIC IN ODISHA STATE, INDIA}

A Nye, M Cusack, P Marelli, E Norris, C Morris. Paediatric Clinic, Love the One India, Berhampur, Odisha, India

10.1136/archdischild-2020-rcpch.390
Introduction Odisha State had the third worst health index ranking among Indian states in 2017-2018. Relative to India as a whole, it has significantly worse infant mortality rate, under 5 mortality rate, and vaccination coverage. Although free public healthcare should be provided for those living below the poverty line, poor and vulnerable children are often denied medical treatment due to institutional bias.

Our charity provides free healthcare, childcare and education for poor and underprivileged children. The clinic provides primary health care for children enrolled in the charity's school and preschools; and Paediatric care for children with disabilities or chronic disease. A disproportionately high number have significant medical conditions, as they are unable to access quality health care via conventional means.

Aims To describe the epidemiology of our patients and the range of conditions seen.

Methods The notes of all Paediatric patients who attended the clinic from September 2018 to August 2019 were reviewed.

Results Over the year, there were 1008 patient encounters. $57 \%$ were by males. The age range was from 1 month to 15 years (median 6 years). 63\% of encounters were for management of acute illness, $11 \%$ were due to trauma, and $23 \%$ were related to chronic disease management. The most common diagnoses were lower respiratory tract infection, viral upper respiratory tract infection, tonsillitis, gastroenteritis and dental problems. Of the acute infections, it was presumed that $49 \%$ were bacterial, 39\% viral, 9\% parasitic and 5\% fungal. 'Tropical' infections encountered include typhoid, TB, dengue fever and HIV. Of the patient encounters that related to chronic diseases, the most common underlying diagnosis was cerebral palsy. Other significant long-term conditions include: sickle cell disease, thalassaemia, spina bifida, hydrocephalus, congenital heart disease, diabetes mellitus and hepatocellular carcinoma.

Conclusion Without this clinic, many of the children would have been unable to access healthcare, and may have experienced increased long-term morbidity or mortality. Children, including those with disabilities, are now able to access appropriate and prompt management of acute and chronic illness. We have demonstrated the impact a low-resource clinic can have, and hope to replicate this model across the state.

\section{G453(P) MODIFIED SPIKES, A NOVEL APPROACH TO COUNSELLING PARENTS OF PREMATURE BABIES}

ZG Abusalah. Neonatal Intensive Care Unit, Mediclinic City Hospital, Dubai, UAE

\subsection{6/archdischild-2020-rcpch.391}

Introduction Counselling of parents expecting a preterm baby is a challenging experience that requires special expertise and knowledge. Despite its importance, there is no standard approved approach to conduct it.

Aims

- To highlight the importance of effective communication with parents.

- To suggest a structured approach for counselling.

Methods The presentation will provide an overview of principles and contents of the counselling session. Although this has been the subject of several reviews and statements, there is a lack of a structured approach for conducting the consultation. 